\title{
Linking young men who have sex with men (YMSM) to STI physicians: a nationwide cross-sectional survey in China
}

Bolin Cao ${ }^{1,2+}$, Peipei Zhao ${ }^{3 \dagger}$, Cedric Bien², Stephen Pan², Weiming Tang ${ }^{2,4}$, Julia Watson ${ }^{4}$, Guodong Mi $^{5}$, Yi Ding $^{3}$, Zhenzhou Luo ${ }^{3}$ and Joseph D. Tucker $2,4,6^{*}$

\begin{abstract}
Background: Many young men who have sex with men (YMSM) are reluctant to seek health services and trust local physicians. Online information seeking may encourage YMSM to identify and see trustworthy physicians, obtain sexual health services, and obtain testing for sexually transmitted infections (STIs). This study examined online STI information seeking behaviors among Chinese YMSM and its association with offline physician visits.

Methods: We conducted a nationwide online survey among YMSM through WeChat, the largest social media platform in China. We collected information on individual demographics, sexual behaviors, online STI information seeking, offline STI testing, and STI physician visits. We examined the most commonly used platforms (search engines, governmental websites, counseling websites, generic social media, gay mobile apps, and mobile medical apps) and their trustworthiness. We assessed interest and willingness to use an MSM-friendly physician finder function embedded within a gay mobile app. Logistic regression models were used to examine the correlation between online STI information searching and offline physician visits.

Results: A total of 503 men completed the survey. Most men (425/503, 84.5\%) searched for STI information online. The most commonly used platform to obtain STI information were search engines (402/425, 94.5\%), followed by gay mobile apps (201/425, 47.3\%). Men reported high trustworthiness of information received from gay mobile apps. Men also reported high interest $(465 / 503,92.4 \%)$ and willingness $(463 / 503,92.0 \%)$ to use a MSM-friendly physician finder function within such apps. Both using general social media (aOR =1.14, 95\%Cl: 1.04-1.26) and mobile medical apps $(\mathrm{aOR}=1.16,95 \% \mathrm{Cl}: 1.01-1.34)$ for online information seeking were associated with visiting a physician.

Conclusion: Online STI information seeking is common and correlated with visiting a physician among YMSM. Cultivating partnerships with the emerging mobile medical apps may be useful for disseminating STI information and providing better physician services to YMSM.
\end{abstract}

Keywords: MSM, Social media, HIV, STIs, China

\footnotetext{
* Correspondence: jdtucker@med.unc.edu

${ }^{\dagger}$ Equal contributors

${ }^{2}$ University of North Carolina Project - China, Guangzhou, China

${ }^{4}$ School of Medicine, University of North Carolina at Chapel Hill, Chapel Hill,

North Carolina, USA

Full list of author information is available at the end of the article
}

(c) The Author(s). 2018 Open Access This article is distributed under the terms of the Creative Commons Attribution 4.0 International License (http://creativecommons.org/licenses/by/4.0/), which permits unrestricted use, distribution, and reproduction in any medium, provided you give appropriate credit to the original author(s) and the source, provide a link to the Creative Commons license, and indicate if changes were made. The Creative Commons Public Domain Dedication waiver (http://creativecommons.org/publicdomain/zero/1.0/) applies to the data made available in this article, unless otherwise stated. 


\section{Background}

Young men who have sex with men (YMSM) are disproportionately affected by HIV and other sexually transmitted infections (STIs), yet are often reluctant to obtain healthcare services [1-4]. YMSM, between the ages of 16 and 30, may be at higher risk of HIV acquisition than older MSM because they may be more likely to be sexually active, suffer from power imbalances in relationships, and report higher rates of condomless sex and substance use [5]. As a result, YMSM require more evidence-based, MSM-friendly healthcare services. Decentralization of healthcare services may improve service quality and coverage [6]. Decentralization refers to transferring clinical services away from a single organizational authority and towards multiple sites. However, service decentralization may also result in inconsistent quality of health services [7], making it difficult to meet the unique needs of YMSM. Physician mistrust and fear of discrimination also discourage YMSM from obtaining health services [3, 4], and thus may affect timely treatment and linkage to care [2]. In order to improve sexual health services and reduce HIV/STI transmission, linkage to care of YMSM to MSMfriendly physicians is urgently needed.

YMSM report inadequate HIV/STI information and insufficient healthcare seeking [8]. The proportion of MSM who visit a STI physician in clinic is low; only $36 \%$ of MSM with suspected STI have sought STI treatment in clinics in China [9]. YMSM attending an STI clinic may experience dual stigma stemming from same-sex practices and the STI treatment-seeking [10]. Missed office visits are also common for MSM living with HIV, leading to a higher likelihood of poor HIV-related outcomes [11]. At the same time, YMSM are increasingly using the Internet to seek health information [12, 13], particularly HIV/STI information $[14,15]$. This may be an opportunity for enhancing the delivery of HIV/STI information. Online information can empower YMSM with STI knowledge and encourage them to visit a physician [16-18]. Some studies have found that individuals who seek sexual health information online show an increase in safe sex behavior [17, 19], HIV/STI testing [20, 21], and service access [22].

When seeking health information online, multiple platforms are available. Search engines are a commonly used platform to initiate the searching process [23, 24]. Governmental websites offer official and authoritative health information $[25,26]$. Counseling websites allow users to ask or answer health-related questions. In contrast, social media platforms allow users to generate health information available for searching. Social media platforms have also grown to include gay mobile apps and mobile medical apps, which characterize two-way interaction and emphasize connection [27]. Among online informational platforms, social media is emerging as an effective method of disseminating health information $[28,29]$. Social media is an online platform that facilitates the creation and sharing of information via virtual communities and networks, and features participation, openness, conversation, and connectedness [27]. Social media can be used to collect the wisdom of crowds, build peer-mentored communities, and deliver HIV/STI prevention services [30]. Social media use is particularly prevalent among adolescents and young adults; and in some contexts, up to $30 \%$ of young people use social media to obtain health information [13]. Social media-based health interventions targeting MSM have been found to be feasible and acceptable among YMSM at high risk [31, 32].

China has a large population of YMSM who use online information seeking platforms. Over 695 million people in China use social media [33], and gay-specific social media platforms such as "Blued" have over 27 million users in China [21]. Chinese YMSM have an HIV and syphilis prevalence of 6.7 and $8.3 \%$, respectively [34]. This is likely related to low HIV/STD knowledge [35], high rates of unprotected anal intercourse [36], perceived low risk of HIV infection, and fears of being stigmatized [37]. Chinese YMSM are increasingly using online resources to seek partners as well as obtain sexual health information [38]. The aim of this study is to examine the relationship between online STI information seeking and offline STI physician visits among YMSM. We also sought to examine the role of social media as a source of STI information and as a method of linking care to STI healthcare providers.

\section{Methods}

\section{Study design and participants}

We conducted a cross-sectional, nationwide online survey from May 27 to May 30, 2017. A convenience sample of participants were recruited through three subscription accounts on the social media platform WeChat, the most popular platform in China. The three accounts included the official account of Blued, the largest gay app with 28 million active users, and the official accounts of two large HIV prevention organizations in China (Qingtong in North China and SESH in South China). Participants accessed the survey through a link attached to a HIV-related article on each WeChat account.

We developed the survey following the Checklist for Reporting Results of Internet E-Surveys (CHERRIES) [39]. The survey questionnaire was field-tested by twenty YMSM in April 2017, and their feedback was incorporated in finalizing the survey questionnaire. Field test data were not included in the final dataset for analysis.

Eligible men were born biologically male, between 16 and 30 years old, had anal or oral sex with men, and had seen a physician in the last 24 months. Physician visits were defined as seeing a physician in clinic for any reason. 
We chose to recruit participants with physician visiting experiences in the past 24 months so they were able to provide and recall their physician visiting behaviors. Participants were asked to sign an electronic informed consent form when starting the survey, and participants received a small phone credit reimbursement $(\sim 7.50$ USD) as a reward upon the completion of survey.

\section{Measures}

Demographic characteristics measured in the study included age, level of education (high school or below, some college, college and above), annual income, current residence (urban or rural), occupation (student or nonstudent), and sexual orientation (gay, bisexual, heterosexual, or other). Participants were asked about their sexual behaviors, including the number of sex partners in the last three months and condomless anal intercourse.

We examined STI testing history and STI physician visiting behavior as outcomes in this study. STI testing history was measured by whether participants had ever tested for HIV, syphilis, hepatitis B, or hepatitis C (Yes/ No). Having tested for at least one of four sexually transmitted diseases was considered as having STI testing history (Yes). STI physician visiting behavior was measured by whether participants had ever visited a physician for any STI or HIV (Yes/No).

Participants were asked whether they had searched for STI information online in the past 24 months (Yes/NO). If yes, they were asked details regarding the online platforms used, searching on symptoms or searching for services, and perceived trustworthiness of the searching results. Online platforms for STI information were categorized into 6 groups: search engines (i.e., Google, Baidu), governmental websites (i.e., Center for Disease Control websites), counseling websites (i.e., 39 HealthNet), generic social media (i.e., WeChat, Weibo), gay mobile apps (i.e. Blued, Grindr) and mobile medical apps (i.e. Pingan Good Doctor App). The survey also included two questions regarding willingness and interest in use of a MSM-friendly doctors finding function in gay mobile Apps. MSM-friendly physicians referred to physicians who meet essential competencies for serving MSM, focusing on prevention and treatment in the survey [40].

\section{Statistical analysis}

We conducted descriptive analyses of participant characteristics and online information searching behaviors. We used bivariate and multivariate logistic regression to examine the association between online health information seeking and offline physician visits. Multivariate logistical analyses adjusted variables including age, education, and income.

\section{Results}

\section{Participant characteristics}

In total, 26,952 individuals viewed the HIV-related article on WeChat, 1689 men clicked the online survey link, and 503 eligible respondents completed the survey. Of the 503 men, the average age was $23.9 \pm 3.5$ years old. In our study, $20.3 \%$ of men were between ages 16 and $20,44.3 \%$ between 21 and 25, and $35.4 \%$ between 26 and 30 , compared with $33.9,35.8$, and $30.2 \%$, respectively, in the 2010 national census [41]. Geographically, participants in our study were from, in a descending order of frequency: Eastern China $(61.6 \%, n=310)$, Western China $(17.9 \%, n=90)$, Central China $(14.3 \%, n=72)$, Northeast China $(6.2 \%, \mathrm{n}=31)$, compared with $40.2,25$. $8,26.8$, and $7.2 \%$ respectively, in the national census [42]. Most of them lived in urban areas (85.9\%), had a college degree or above (45.3\%), had an annual income less than CNY 60,000 (USD 9200, 79.5\%), and selfidentified as gay (83.5\%).

Around three-quarters $(73.0 \%)$ of participants had no more than one sex partner in the past 3 months and 75 . $3 \%$ used condom in the last sex encounter. Most (91.5\%) participants had tested for at least one type of STI in their lifetime, $85.7 \%$ had tested for HIV at least once, and $55.1 \%$ had tested for syphilis at least once, $64.2 \%$ had ever tested for Hepatitis B and $41.0 \%$ had ever tested for Hepatitis C. Of the participants, $57.9 \%$ visited a STI physician in the past 24 months (Table 1).

\section{Interest and willingness of using a MSM-friendly physician finding function}

Almost all men (92.4\%) indicated they were at least somewhat interested in using a MSM-friendly physician finding function. Only $8 \%(38 / 503)$ participants were not interested. 92.0\% (463/503) were willing to use this kind of function within gay networking apps.

\section{Online information seeking behavior}

Among participants who had completed the survey, 84. $5 \%(425 / 503)$ had searched for STI information online. A majority of the participants (94.5\%) had used search engines, roughly half (47.3\%) had used gay mobile apps, and $35.5 \%$ had used generic social media. Roughly one in ten men $(11.8 \%)$ had used mobile medical apps to search for STI information.

Among those who sought STI information online, perceived trustworthiness of sexual health information from different platforms was highest for governmental websites (85.3\%), and gay mobile apps (77.1\%). Most participants used generic social media platforms $(94.0 \%)$ and gay mobile apps (90.5\%) to seek information for symptoms. In addition, nearly two thirds used gay mobile apps (65.2\%) to search for sexual health services (Table 2). 
Table 1 Demographical and behavioral characteristics of YMSM participants who had visited a physician in the past 24 months in China, 2017 ( $n=503)$

\begin{tabular}{lll}
\hline Characteristics & Total \\
\cline { 2 - 2 } & $\mathrm{n}$ & $\%$ \\
\hline
\end{tabular}

Age (Mean: 23.92 and SD:3.54)

20.3

$16-20$

44.3

$21-25$

178

35.4

26-30

High school/below

Some college

College/bachelors above

28.0

Annual income (USD)

$$
<2700
$$

$2700-5500$

$5501-9200$

$9201-15,000$

$>15,000$

Residency

Rural
Urban

Occupation

Student

Sexual orientation

Gay

Bisexual

Heterosexual

Unsure/other

20

Number of anal sex partners in the past 3 months

$$
\begin{array}{ll}
0-1 & 367 \\
\text { Multiple } & 136
\end{array}
$$

Used a condom during last MSM sexual encounter ${ }^{2}$

Yes

No

Ever HIV tested

$$
\text { Yes }
$$

No

HIV serostatus

Positive
Negative

Never tested or Not got results

Ever syphilis tested

No
Table 1 Demographical and behavioral characteristics of YMSM participants who had visited a physician in the past 24 months in China, 2017 ( $n=503$ ) (Continued)

\begin{tabular}{lll}
\hline Characteristics & \multicolumn{2}{l}{ Total } \\
\cline { 2 - 3 } & $\mathrm{n}$ & $\%$ \\
\hline Positive & 40 & 8.0 \\
Negative & 237 & 47.1 \\
$\quad$ Never tested & 226 & 44.9 \\
Ever Hepatitis B tested & & \\
$\quad$ Yes & 323 & 64.2 \\
No & 180 & 35.8 \\
Ever Hepatitis C tested & & \\
Yes & 206 & 41.0 \\
No & 297 & 59.0 \\
Online STI information seeking & & \\
Yes & 425 & 84.5 \\
No & 78 & 15.5
\end{tabular}

Interest in using the MSM-friendly physician function in a gay mobile App

$\begin{array}{lll}\text { Very Interested } & 313 & 62.2 \\ \text { Somewhat interested } & 152 & 30.2 \\ \text { Somewhat not interested } & 36 & 7.2 \\ \text { Very not interested } & 2 & 0.4\end{array}$

Willingness to use the MSM-friendly physician function in a gay mobile App

$\begin{array}{lll}\text { Yes } & 463 & 92.0 \\ \text { No } & 40 & 8.0\end{array}$

Ever STI tested ${ }^{b}$

$\begin{array}{lll}\text { Yes } & 460 & 91.5\end{array}$

$\begin{array}{lll}\text { No } & 43 & 8.5\end{array}$

Visited a STI physician in the past 24 months $^{c}$

Yes $291 \quad 57.9$

$\begin{array}{lll}\text { No } & 212 & 42.1\end{array}$

Searching platforms ${ }^{d}$

$\begin{array}{lll}\text { Search engine } & 402 & 94.5 \\ \text { Governmental websites } & 156 & 36.7 \\ \text { Counseling websites } & 72 & 16.9 \\ \text { Generic social media } & 151 & 35.5 \\ \text { Gay mobile app } & 201 & 47.3 \\ \text { Mobile medical app } & 50 & 11.8\end{array}$

${ }^{a}$ The total number for condom use was 474 , as 29 participants did not have anal sex with other men.

${ }^{\mathrm{b}} \mathrm{STI}$ testing included HIV, syphilis, hepatitis B \&C.

'STI physician visits included visiting a physician for STI and HIV.

${ }^{d}$ The total number of YMSM who searched STI information online was 425, which was the denominator of this item

Factors associated with offline physician visiting behavior Binary logistic regression results showed that generic social media use $(\mathrm{OR}=1.18,95 \% \mathrm{CI}: 1.08-1.29)$ and gay

Syphilis serostatus 
mobile $(\mathrm{OR}=1.10,95 \% \mathrm{CI}: 1.01-1.19)$, instead of mobile medical app use $(\mathrm{OR}=1.11,95 \% \mathrm{CI}=0.97-1.26)$, were significantly associated with STI physician visits. In multivariate logistic analyses, generic social media use (aOR $=1.14,95 \% \mathrm{CI}: 1.04-1.26)$ and mobile medical app use $(\mathrm{aOR}=1.16$, 95\%CI: $1.01-1.34$ ) were significantly associated with STI physician visits (Table 3). In addition, the binary logistic regression results showed online seeking for symptoms $(\mathrm{aOR}=2.50,95 \% \mathrm{CI}: 1.74-3.60)$ and services $(\mathrm{aOR}=2.42$, 95\%CI: $1.65-3.54)$ were correlated with offline STI physician visits. The multivariate analyses also suggested that both online seeking for symptoms $(\mathrm{aOR}=2.02,95 \% \mathrm{CI}: 1.34-3.04)$ and services $(\mathrm{aOR}$ $=1.95$, 95\%CI: $1.28-2.99$ ) were correlated with STI physician visit offline.

\section{Discussion}

This study examines YMSM's online health information seeking behavior and its relationship with offline STI physician visits. This study extends the literature by exploring the role of social media as an emerging source of sexual health information. A majority of study participants had used online search engines and various forms of social media to seek sexual health information. YMSM considered gay mobile apps to be trustworthy sources of sexual health information, and utilized apps to seek health services. We also observed an association between online information seeking and offline physician visits, and found high rates of interest and willingness to use a MSM-friendly physician finding function.

We found that a majority of YMSM used generic social media and gay apps to seek sexual health information. This finding is consistent with prior surveys that have supported the emerging role of social media as searching tools [15, 23, 43, 44]. Compared with obtaining information from clinics and other institutions, online STI information seeking may be preferable because of its relatively anonymous, convenient, and confidential search process [45-47]. Social media platforms extend these advantages with increased adaptability, usability, and customizability [48]. Users can generate content and improve information quality through repeated, iterative processes $[49,50]$. Individuals tend to have more trust in information shared by friends and acquaintances on social media compared with conventional sources [51]. With increasing integration of social media into daily communication habits [52], social media platforms represent novel opportunities for STI information dissemination.

YMSM indicated high levels of trustworthiness of STI information on gay mobile apps. Gay mobile apps were next only to authoritative governmental websites in the perceived trustworthiness. High levels of media use may build trust in certain media platforms $[53,54]$. The most popular gay mobile app in China is accessed on average 227.5 times a week per user [55]. Gay mobile apps also expand opportunities for sexual health services to reach YMSM who may fear disclosing their same-sex behaviors in other contexts $[56,57]$. MSM-exclusive platforms may also provide a feeling of safety among YMSM, and thus build trustworthiness toward the information on gay mobile apps [58]. Information about HIV/STIs and sexual health services on gay mobile apps can increase YMSM's exposure and access to guidance and services of prevention, linkage to care, and treatment.

As YMSM have demonstrated high rates of Internet use for information seeking [5], improving access to offline healthcare services through online information is critical. In this study, we observed that online information seeking among YMSM was correlated with offline STI physician visits. In particular, seeking for symptoms was strongly associated with offline STI physicians, indicating that YMSM tend to more likely visit physicians in case of symptoms than screening of asymptomatic STI. Online informationbased interventions have been implemented in many fields to promote health care $[59,60]$, including increasing HIV/ STI testing [61] and antiretroviral therapy (ART) adherence [62]. Online information seeking may help empower YMSM with medical literacy, enable self-advocacy, and increase confidence before seeing a physician [63, 64]. Nonetheless, the prevalence of misinformation online can also

Table 2 Approaches for YMSM participants to seek for health information online in China, $2017(n=425)$

\begin{tabular}{llll}
\hline Platforms & $\begin{array}{l}\text { Perceived } \\
\text { Trustworthiness } \\
\text { N(\%) }\end{array}$ & Seeking about symptoms ${ }^{\mathrm{a}}$ & Seeking for services $^{\mathrm{b}}$ \\
\hline Search engine & $243 / 402(60.4 \%)$ & & $\mathrm{N}(\%)$ \\
Governmental websites & $133 / 156(85.3 \%)$ & & \\
Counseling websites & $54 / 72(75.0 \%)$ & $142 / 151(94.0 \%)$ & $115 / 151(76.2 \%)$ \\
Generic social media & $93 / 151(61.6 \%)$ & $182 / 201(90.5 \%)$ & $131 / 201(65.2 \%)$ \\
Gay mobile App & $155 / 201(77.1 \%)$ & $44 / 50(88.0 \%)$ & $40 / 50(80.0 \%)$ \\
\hline Mobile medical App & $37 / 50(74.0 \%)$ & & \\
\hline
\end{tabular}

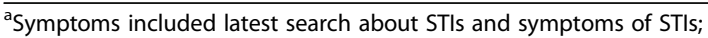

bervices included viewing online comments on physicians and making an appointment.

${ }^{c}$ Mobile medical apps referred to apps that provide medical counselling and treatment service, such as Ping An Good Doctor App and Good Doctor Online App 
Table 3 Multivariate logistical regression on health information seeking on social media with offline physician-visiting behaviors of YMSM participants in China, $2017(n=503)$

\begin{tabular}{|c|c|c|c|c|}
\hline & STI testing ${ }^{a}$ & STI physician & & \\
\hline & OR $95 \% \mathrm{Cl}$ & $\mathrm{aOR}^{\mathrm{c}} 95 \% \mathrm{Cl}$ & OR $95 \% \mathrm{Cl}$ & aOR 95\% C \\
\hline Platform use & & & & \\
\hline Generic social media use & $\begin{array}{l}1.44^{* *} \\
(1.10-1.88)\end{array}$ & $\begin{array}{l}1.39^{*} \\
(1.06-1.81)\end{array}$ & $\begin{array}{l}1.18^{* * *} \\
(1.08-1.29)\end{array}$ & $\begin{array}{l}1.14^{* *} \\
(1.04-1.26)\end{array}$ \\
\hline Gay mobile App use & $\begin{array}{l}1.60^{* * *} \\
(1.19-2.16)\end{array}$ & $\begin{array}{l}1.62^{* * *} \\
(1.20-2.19)\end{array}$ & $\begin{array}{l}1.10^{*} \\
(1.01-1.19)\end{array}$ & $\begin{array}{l}1.04 \\
(0.95-1.14)\end{array}$ \\
\hline Mobile medical App use & $\begin{array}{l}1.12 \\
(0.85-1.47)\end{array}$ & $\begin{array}{l}1.12 \\
(0.85-1.47)\end{array}$ & $\begin{array}{l}1.11 \\
(0.97-1.26)\end{array}$ & $\begin{array}{l}1.16^{*} \\
(1.01-1.34)\end{array}$ \\
\hline Seeking behavior & & & & \\
\hline Online seeking for symptoms & $\begin{array}{l}4.99^{* * *} \\
(2.26-10.98)\end{array}$ & $\begin{array}{l}4.91^{* * *} \\
(2.18-11.09)\end{array}$ & $\begin{array}{l}2.50^{* * *} \\
(1.74-3.60)\end{array}$ & $\begin{array}{l}2.02^{* * *} \\
(1.34-3.04)\end{array}$ \\
\hline Online seeking for services & $\begin{array}{l}6.86^{* * *} \\
(2.41-19.52)\end{array}$ & $\begin{array}{l}7.21^{* * *} \\
(2.50-20.91)\end{array}$ & $\begin{array}{l}2.42^{* * *} \\
(1.65-3.54)\end{array}$ & $\begin{array}{l}1.95^{* *} \\
(1.28-2.99)\end{array}$ \\
\hline Perception & & & & \\
\hline Perceived trustworthiness of searching results & $\begin{array}{l}3.42^{* * *} \\
(1.80-6.47)\end{array}$ & $\begin{array}{l}2.86^{* *} \\
(1.43-5.72)\end{array}$ & $\begin{array}{l}2.00^{* * *} \\
(1.37-2.93)\end{array}$ & $\begin{array}{l}1.54 \\
(0.99-2.39)\end{array}$ \\
\hline
\end{tabular}

${ }^{a}$ Multivariate logistical analyses of STI testing controlled age, education, income, condom use and sex partner number.

${ }^{b}$ Multivariate logistical analyses of STI physician visiting controlled age, education, income, condom use, sex partner number, HIV status and syphilis status. c aOR refers to adjusted odds ratio

${ }^{*} p<0.05,{ }^{* *} p<0.01,{ }^{* * *} p<0.001$

make information seeking difficult [8]. Linking the highquality, and accurate information to offline health services for YMSM will be critical in developing potential social media health interventions.

Most men were interested and willing to use a MSMfriendly physician finding function within gay-specific apps. This finding highlights the need for creating a friendly and comfortable environment to provide clinic services for MSM [65]. In the context of decentralization of health services, informing and suggesting STI physicians based on the geographical locations within gayspecific apps can improve healthcare accessibility and approachability [7]. In addition, many YMSM may not access health services in fear of being outed and healthcare discrimination [66]. Identifying and recommending MSM-friendly physicians can remove some barriers that defer YMSM to visit a physician and access healthcare resources.

This study has several limitations. First, participants were all recruited through social media platforms with internet access and social media use, which may overestimate the rate of online information seeking. Second, the participants were required to have visited a physician in the past 24 months; this may also result in an overestimate of the rate of visiting physicians. Third, participants were relatively well-educated, had higher income and had higher proportion living in Eastern China, and our findings may not be generalizable in other contexts or settings. Fourth, our survey did not distinguish those who sought STI information online once or repeatedly sought STI information online. Fifth, this study used a cross-sectional survey and thus could not determine any causal relationships. Finally, men self-reported sexual behaviors and healthcare seeking behaviors, introducing potential recall or social disability bias.

\section{Conclusion}

Gay mobile apps and other social media platforms represent a unique opportunity to engage YMSM at high risk for HIV and STIs. Social media can be leveraged to disseminate STI information to YMSM. In addition, social media can be utilized to promote sexual health services, such as physician-finding functions. Our findings highlight the need to develop strategies to link YMSM to MSM-friendly physicians and health services.

\section{Abbreviations \\ aOR: Adjusted odds ratio; CHERRIES: Checklist for Reporting Results of Internet E-Surveys; HIV: Human immunodeficiency virus; MSM: Men who have sex with men; OR: Odds ratio; STI: Sexually transmitted infections; YMSM: Young men who have sex with men}

\section{Acknowledgements}

We would like to thank all the members in SESH group and Nanshan Chronic Disease Control Center for support, and the study participants who contributed to this study.

\section{Funding}

This study was funded by Shenzhen Nanshan Center for Chronic Disease Control, National Institutes of Health [National Institute of Allergy and Infectious Diseases 1R01Al114310]; UNC-South China STI Research Training Centre [Fogarty International Centre 1D43TW009532]; UNC Center for AIDS Research [National Institute of Allergy and Infectious Diseases 5P30AI050410]; National Social Science Foundation of China [16CXW031]; Youth Talent Grant of Guangdong Province [2017WQNCX129]; Social Science Young Teacher Supporting Project of Shenzhen [18QNFC46]; and the Bill \& Melinda Gates Foundation to the MeSH Consortium (BMGF-OPP1120138). This publication 
was also supported by Grant Number UL1TR001111 from the National Center for Advancing Translational Sciences (NCATS) at the National Institutes of Health.

\section{Availability of data and materials}

The datasets used and/or analysed during the current study are available from the corresponding author on reasonable request.

\section{Authors' contributions}

JT and ZL conceived the study, JT, BC, JW and WT designed the methods. $B C$ and $P Z$ did the analyses. $B C$ and $P Z$ drafted the manuscript with input from CB, GM, YD, ZL and JT. CB and GM helped analyze the data and substantially revised the manuscript. SP, JW, WT and YD also contributed to study design and implementation. All authors critically revised the manuscript. All authors read and approved the final manuscript.

\section{Ethics approval and consent to participate}

The study was reviewed and approved by the Institutional Review Board (IRB) of the Guangdong Provincial Center for Skin Diseases and STI Control (Guangzhou, China) and the University of North Carolina at Chapel Hill (North Carolina, United States) (No: IGHID 11706) before launch. Participants were asked to sign an electronic informed consent form when starting the survey.

\section{Competing interests}

The authors declare that they have no competing interests.

\section{Publisher's Note}

Springer Nature remains neutral with regard to jurisdictional claims in published maps and institutional affiliations.

\section{Author details}

'School of Media and Communication, Shenzhen University, Shenzhen, China. ${ }^{2}$ University of North Carolina Project - China, Guangzhou, China. ${ }^{3}$ Shenzhen Nanshan Chronic Disease Control Center, Shenzhen, China. ${ }^{4}$ School of Medicine, University of North Carolina at Chapel Hill, Chapel Hill, North Carolina, USA. ${ }^{5}$ Blued, Beijing, China. ${ }^{6}$ London School of Hygiene and Tropical Medicine, London, UK

Received: 5 December 2017 Accepted: 10 May 2018

Published online: 18 May 2018

\section{References}

1. Guo Y, Li X, Fang X, Lin X, Song Y, Jiang S, et al. A comparison of four sampling methods among men having sex with men in China: implications for HIV/STD surveillance and prevention. AIDS Care. 2011;23:1400-9.

2. Remien RH, Bauman LJ, Mantell JE, Tsoi B, Lopez-Rios J, Chhabra R, et al. Barriers and facilitators to engagement of vulnerable populations in HIV primary care in New York city. JAIDS J Acquir Immune Defic Syndr. 2015;69: S16-24.

3. Malta M, Bastos Fl, Strathdee SA, Cunnigham SD, Pilotto JH, Kerrigan D. Knowledge, perceived stigma, and care-seeking experiences for sexually transmitted infections: a qualitative study from the perspective of public clinic attendees in Rio de Janeiro. Brazil BMC Public Health. 2007;7:18.

4. Ahsan Ullah AKM. HIV/AIDS-related stigma and discrimination: a study of health care providers in Bangladesh. J Int Assoc Phys AIDS Care. 2011;10:97104.

5. World Health Organization. HIV and young men who have sex with men. 2015;

6. Hipgrave D, Guo S, Mu Y, Guo Y, Yan F, Scherpbier R, et al. Chinese-style decentralization and health system reform. PLoS Med. Public Libr Sci. 2012; 9:e1001337.

7. Beyrer C, Wirtz AL, Walker D, Johns B, Sifakis F, Baral SD. The global HIV epidemics among men who have sex with men. Washington, DC: World Bank; 2011.

8. Xu J-J, Yu Y-Q, Hu Q-H, Yan H-J, Wang Z, Lu L, et al. Treatment-seeking behaviour and barriers to service access for sexually transmitted diseases among men who have sex with men in China: a multicentre cross-sectional survey. Infect Dis Poverty. 2017;6:15.

9. Schmidt AJ, Marcus U. Self-reported history of sexually transmissible infections (STIS) and STI-related utilization of the German health care system by men who have sex with men: data from a large convenience sample. BMC Infect Dis. 2011;11:132.

10. Horberg MA, Hurley LB, Silverberg MJ, Klein DB, Quesenberry CP, Mugavero MJ. Missed office visits and risk of mortality among HIV-infected subjects in a large healthcare system in the United States. AIDS Patient Care STDs. 2013;27:442-9.

11. Lenhart A, Purcell K, Smith A, Zickuhr K. Social media \& mobile Internet use among teens and young adults. Millennials. [Internet]. Pew Internet Am. Life Proj. 2010 [cited 2017 Jul 18]. p. 1-16. Available from: https://eric.ed.gov/ ?id=ED525056

12. Wartella E, Rideout V, Zupanic H, Beaudoin-Ryan L, Lauricella A. Teens, health, and technology: a national survey. Media Commun. 2015;4:13-23.

13. Suzuki LK, Calzo JP. The search for peer advice in cyberspace: an examination of online teen bulletin boards about health and sexuality. J Appl Dev Psychol. 2004;25:685-98.

14. Buhi ER, Daley EM, Oberne A, Smith SA, Schneider T, Fuhrmann HJ. Quality and accuracy of sexual health information web sites visited by young people. J Adolesc Health. 2010;47:206-8.

15. Hooper S, Rosser BRS, Horvath KJ, Oakes JM, Danilenko G. An online needs assessment of a virtual community: what men who use the internet to seek sex with men want in internet-based HIV prevention. AIDS Behav. 2008;12:867-75.

16. Mustanski B, Lyons T, Garcia SC. Internet use and sexual health of young men who have sex with men: a mixed-methods study. Arch Sex Behav. 2011;40:289-300.

17. Zhang D, Bi P, Lv F, Tang H, Zhang J. Internet use and risk behaviours: an online survey of visitors to three gay websites in China. Sex Transm. 2007; 83:571-6.

18. Bowen AM, Williams ML, Daniel CM, Clayton S. Internet based HIV prevention research targeting rural MSM: feasibility, acceptability, and preliminary efficacy. J Behav Med. 2008:31:463-77.

19. Blas MM, Alva IE, Carcamo CP, Cabello R, Goodreau SM, Kimball AM, et al. Effect of an online video-based intervention to increase HIV testing in men who have sex with men in Peru. PLoS One 2010;5:e10448.

20. Cao B, Liu C, Durvasula M, Tang W, Pan S, Saffer A, et al. Social media engagement and HIV testing among men who have sex with men in China. J Med Internet Res. 2017;19:e394.

21. Xiao N, Sharman R, Rao HR, Upadhyaya S. Factors influencing online health information search: an empirical analysis of a national cancer-related survey. Decis Support Syst. 2014;57:417-27

22. Choudhury M De, Morris M, White R. Seeking and sharing health information online: comparing search engines and social media. Proc SIGCHI Conf Hum Factors Comput Syst. 2014. p. 1365-76.

23. Gray NJ, Klein JD, Noyce PR, Sesselberg TS, Cantrill JA. Health informationseeking behaviour in adolescence: the place of the internet. Soc Sci Med. 2005:60:1467-78.

24. Eastin MS. Credibility assessments of online health information: the effects of source expertise and knowledge of content. J Comput-Mediat Commun. 2001;6:0. Blackwell Publishing Ltd

25. Rains SA, Karmikel CD. Health information-seeking and perceptions of website credibility: examining web-use orientation, message characteristics, and structural features of websites. Comput Hum Behav. 2009;25:544-53.

26. Mayfield A. What is social media. Networks. 2008;1(4):36.

27. Vance K, Howe W, Dellavalle RP. Social internet sites as a source of public health information. Dermatol Clin. 2009;27:133-6.

28. Scanfeld D, Scanfeld V Larson EL. Dissemination of health information through social networks: twitter and antibiotics. Am J Infect Control NIH Public Access. 2010;38:182-8.

29. Tso LS, Tang W, Li H, Yan HY, Tucker JD. Social media interventions to prevent HIV: a review of interventions and methodological considerations. Curr Opin Psychol. 2015;9:6-10.

30. Sun C, Stowers J, Miller C, Bachmann L. Acceptability and feasibility of using established geosocial and sexual networking mobile applications to promote HIV and STD testing among men who have sex with. AIDS Behav. 2015;19:543-52.

31. Holloway IW, Rice E, Gibbs J, Winetrobe H, Dunlap S, Rhoades H. Acceptability of smartphone application-based HIV prevention among young men who have sex with men. AIDS Behav. 2014;18:285-96.

32. CNNIC. Statistical Report on Internet Development in China. 2017;

33. Wei S, Zhang H, Wang J, Song D, Duan Y, Yu F, et al. HIV and syphilis prevalence and associated factors among young men who have sex with men in 4 cities in China. AIDS Behav. 2013;17:1151-8. 
34. Dong Z, Xu J, Zhang H, Dou Z, Mi G, Ruan Y, et al. HIV incidence and risk factors in Chinese young men who have sex with men-a prospective cohort study. PLoS One. 2014;9:e97527.

35. Xu J-J, Reilly KH, Lu C-M, Ma N, Zhang M, Chu Z-X, et al. A cross-sectional study of HIV and syphilis infections among male students who have sex with men (MSM) in Northeast China: implications for implementing HIV screening and intervention programs. BMC Public Health. 2011;11:287.

36. Song Y, Li X, Zhang L, Fang X, Lin X, Liu Y, et al. HIV testing behavior among young migrant men who have sex with men (MSM) in Beijing. China AIDS Care. 2011;23:179-86.

37. Bien CH, Best JM, Muessig K, Wei C, Han L, Tucker JD. Gay Apps for Seeking Sex Partners in China: Implications for MSM Sexual Health. AIDS Behavior. 2015:19:941-6.

38. Eysenbach G. Improving the quality of Web surveys: the Checklist for Reporting Results of Internet E-Surveys (CHERRIES). J Med Internet Res. 2004; 6:e34

39. Watson J, Tang W, Pan S, Wu D, Zhao P, Cao B, et al. Out of the Closet, Into the Clinic: Opportunities for Expanding MSM-Competent Services in China. Sex Transm Dis [Internet]. 2018 [cited 2018 May 6];Publish Ahead of Print. Available from: https://journals.lww.com/stdjournal/Abstract/publishahead/ Out_of_the_Closet,_Into_the_Clinic__Opportunities.98295.aspx

40. National Bureau of Statistics. Tabulation on the 2010 population census of the People's Republic of China [Internet]. 2010. Available from: http://www. stats.gov.cn/english/Statisticaldata/CensusData/rkpc2010/indexch.htm

41. National Bureau of Statistics. Statistical communique of the People's Republic of China on the 2017 national economic and social development [Internet]. 2018. Available from: http://www.stats.gov.cn/english/ PressRelease/201802/t20180228_1585666.html

42. Buhi ER, Daley EM, Fuhrmann HJ, Smith SA. An observational study of how young people search for online sexual health information. J Am Coll Health Taylor \& Francis Group. 2009;58:101-11.

43. Zhang $X$, Wen D, Liang J, Lei J. How the public uses social media wechat to obtain health information in China: a survey study. BMC Med Inform Decis Mak. 2017;17:66

44. Zhang D, Gu J, Shao R. A cluster analysis of college students' health information acquisition channel: active seeking and accidental exposure. Chin J Journal Commun. 2015;5:1-7.

45. Morahan-Martin J. How internet users find, evaluate, and use online health information: a cross-cultural review. Cyberpsychol Behav. 2004;7:497-510.

46. Powell J, Inglis N, Ronnie J, Large S. The characteristics and motivations of online health information seekers: cross-sectional survey and qualitative interview study. J Med Internet Res. 2011;13:e20.

47. Yates D, Paquette S. Emergency knowledge management and social media technologies: A case study of the 2010 Haitian earthquake. Int J Inf Manag. 2011;47:6-13.

48. Westerman D, Spence PR, Van Der Heide B. Social media as information source: Recency of updates and credibility of information. J Comput-Mediat Commun. Blackwell Publishing Ltd. 2014;19:171-83.

49. Boyd D. Streams of content, limited attention: the flow of information through social media. Educ Rev. 2010;45:26.

50. Turcotte J, York C, Irving J, Scholl RM, Pingree RJ. News recommendations from social media opinion leaders: effects on media trust and information seeking. J Comput-Mediat Commun Blackwell Publishing Ltd. 2015;20:52035.

51. Quan-Haase A, Young AL. Uses and gratifications of social media: a comparison of Facebook and instant messaging. Bull Sci Technol Soc. 2010; 30:350-61.

52. Hou J, Shim M. The role of provider-patient communication and trust in online sources in internet use for health-related activities. J Health Commun. 2010;15:186-99.

53. Kiousis S. Public trust or mistrust? Perceptions of media credibility in the information age. Mass Commun Soc. 2001;4:381-403.

54. Cheetah Lab. China App rankings in the first Quarter of 2017 [Internet]. 2017 [cited 2017 Aug 7]. Available from: http://lab.cmcm.com/sjfx/2017-0414/170.htm

55. Martinez O, Wu E, Shultz AZ, Capote J, Rios JL, Sandfort T, et al. Still a hardto-reach population? Using social media to recruit latino gay couples for an HIV intervention adaptation study. J Med Internet Res. 2014;16:e113.

56. Straub D, Bruce E, Washington B. Innovative approaches to recruitment of YMSM of color for HIV education and testing services. J Adolesc. 2017:60: s91-2.
57. Miller B. "They're the modern-day gay bar": exploring the uses and gratifications of social networks for men who have sex with men. Comput Hum Behav. 2015;51:476-82.

58. Bryant J, Sanson-Fisher R, Stevenson W, Smits R, Henskens F, Wei A, et al. Protocol of a multi-Centre randomised controlled trial of a web-based information intervention with nurse-delivered telephone support for haematological cancer patients and their support persons. BMC Cancer. 2015;15:295.

59. Maher CA, Lewis LK, Ferrar K, Marshall S, De Bourdeaudhuij I, Vandelanotte $C$. Are health behavior change interventions that use online social networks effective? A systematic review. J Med Internet Res. 2014;16:e40.

60. Rhodes SD, McCoy TP, Tanner AE, Stowers J, Bachmann LH, Nguyen AL, et al. Using social media to increase HIV testing among gay and bisexual men, other men who have sex with men, and transgender persons: outcomes from a randomized community trial. Clin Infect Dis Oxford University Press. 2016;62:1450-3

61. Horvath KJ, Michael Oakes J, Simon Rosser BR, Danilenko G, Vezina H, Rivet Amico K, et al. Feasibility, acceptability and preliminary efficacy of an online peer-to-peer social support ART adherence intervention. AIDS Behav. 2013; 17:2031-44.

62. Lambert SD, Loiselle CG. Health information —seeking behavior. Qual Health Res. 2007;17:1006-19.

63. Lee YJ, Boden-Albala B, Larson E, Wilcox A, Bakken S. Online health information seeking behaviors of Hispanics in New York City: a communitybased cross-sectional study. J Med Internet Res. 2014;16:e176. JMIR Publications Inc.

64. Lim MS, Vella A, Sacks-Davis R, Hellard ME. Young people's comfort receiving sexual health information via social media and other sources. Int J STD AIDS. 2014;25:0956462414527264

65. Magee JC, Bigelow L, DeHaan S, Mustanski BS. Sexual health information seeking online. Health Educ Behav. 2012;39:276-89. SAGE PublicationsSage CA: Los Angeles, CA

\section{Ready to submit your research? Choose BMC and benefit from:}

- fast, convenient online submission

- thorough peer review by experienced researchers in your field

- rapid publication on acceptance

- support for research data, including large and complex data types

- gold Open Access which fosters wider collaboration and increased citations

- maximum visibility for your research: over $100 \mathrm{M}$ website views per year

At BMC, research is always in progress.

Learn more biomedcentral.com/submissions 